\title{
Analysis of Traffic Capacity on Mountainous Two Lane Highway Adding Climbing Lane
}

\author{
Yunwei Meng ${ }^{1,2}$, Hailing $\mathrm{Li}^{2}$, Hejun Chai ${ }^{2}$ and Zongling Yan ${ }^{2}$ \\ ${ }^{1}$ The Key Laboratory of Road and Traffic Engineering, Ministry of Education, Tongji University, 201804,Shanghai, China \\ ${ }^{2}$ China Merchants Chongqing Communications Technology Research \& Design Institute Co., LTD, 400067, Chongqing, China
}

\begin{abstract}
During the construction of mountainous double lane highway, climbing lane plays a certain role for enhancing the traffic capacity. In order to explore traffic capacity improvement effect for different conditions of climbing lane, 20 representative models are chosen, which contain various combinations of alignment and traffic parameters. The changes of traffic capacity, average speed, delays, and saturation in models are obtained before and after the use of a climbing lane by means of numerical simulation. The results show that the use of a climbing lane could improve traffic capacity, average speed, while reducing delays and saturation. The improvement effect is different according to different combinations of alignment and traffic parameters. The research could provide a reference for mountainous climbing lane construction intend.
\end{abstract}

\section{Introduction}

Because of the limitation of geology, topography and engineering investment, two-way two lane highway is common form in mountainous area of China. Two lane highways in mountain area is the main artery, assuming the dual role of the internal and external communication. Its adequate traffic capacity, high safety performance, is particularly important to regional social and economic development. In addition to low alignment parameters, mountainous two lanes are also traffic accident-prone sections, especially in uphill ones. Due to lower travelling speed of trucks, creating a large speed difference between cars, it will significantly reduce the traffic capacity of the road, thereby inducing safety accidents. Adding climbing lane is an effective, economic, environmental and feasible solution to eliminate the phenomenon.

\section{Literature review}

It will form a larger travel impact on the entire road when the length of the continuous uphill road section and the proportion of truck in traffic volume reach peak value. More serious congestion will occur in the impact area, while car adventure temporarily occupy the opposite lane, it will be more likely to cause traffic accidents [1]. Climbing lane is set on a section with severely reduced traffic capacity, which is a special lane for truck travelling. By means of physical separation [2], a lane is added to the right of the main road for continuous uphill section. After trucks traveling some distance, let it back into the main road, which could improve the traffic capacity of the road and traffic safety [3]. Some research found that it is possible to generate traffic bottlenecks in the lane separation and convergence position. It can effectively ease traffic congestion by extending the length of the transition section [4]. Setting up a reasonable climbing lane, it can slow down the occurrence of traffic congestion [5]. The weight power ratio of the truck is the factor that should be considered when setting up the climbing lane, and it is directly related to the climbing performance of the vehicle. Therefore, the weight power ratio of the truck is an important basis for the calculation of longitudinal slope and slope length of the climbing lane [6].

All of the above studies show that setting up the climbing lane is beneficial to improve the traffic capacity of the section. This paper intends to make a comparative analysis of traffic capacity, average speed, delay and saturation before and after setting up the climbing lane. This paper is intended to evaluate the effect of setting up the climbing lane in mountainous highway.

\section{Numerical simulation process}

According to the theory of dynamics and kinematics, the running characteristic of each kind of vehicle can be obtained by calculating. When the vehicle is running on longitudinal section, the vehicle is subjected to the combined action of traction and resistance, and the resistance includes air resistance, rolling resistance, slope resistance and inertia resistance. Before reaching the equilibrium speed, the running process of the vehicle can be simplified as a uniformly deceleration motion. 
VISSUM is used for simulation. It is a kind of traffic simulation modeling tool, which is microscopic and based on time interval and vehicle driving behavior. It can be used to simulate and analyze the traffic operation condition of various road traffic conditions, and it is an effective tool to evaluate road traffic engineering design and road traffic planning. VISSIM simulation system is composed of many modules, and these modules have different functions.

\subsection{Determination of representative vehicle}

According to the survey data combined with the development truck industry, the representative model of the two-lane highway truck in the mountainous area of China is chosen as EQ1228v19D2 of Dongfeng truck. Representative vehicle is used in the process of simulation.

\subsection{Simulation scheme}

The research object of this simulation is the climbing lane of the two lane highway in mountainous area. In general, when the slope of the road is more than or equal to $3 \%$, climbing lane could be proposed.

According to the "Technical Standard of Highway Engineering" (JTG B01-2014), the design speed of the secondary highway is generally $80 \mathrm{~km} / \mathrm{h}, 60 \mathrm{~km} / \mathrm{h}$, and the longitudinal gradient is generally not more than $6 \%$. Taking into account the characteristics of the mountain road, the simulation of the longitudinal slope gradient could be chosen as $3 \%, 4 \%, 5 \%, 6 \%$, and $7 \%$ respectively.

At the same time, the design speed of the secondary highway is $60 \mathrm{~km} / \mathrm{h}$, the maximum slope length of the longitudinal slope is $1200 \mathrm{~m}$, and combined with the time complexity of computer simulation, the slope length of the simulation are chosen as $200 \mathrm{~m}, 300 \mathrm{~m}, 600 \mathrm{~m}, 900 \mathrm{~m}$, $1200 \mathrm{~m}$ respectively.

In this simulation experiment, the mixing ratio of the truck in traffic volume can be chosen as $10 \%, 20 \%, 30 \%$, $40 \%, 50 \%$, and $60 \%$ respectively.

Combined with the actual traffic of the secondary highway in mountain area and the time complexity of computer simulation, the simulated traffic can be used $1000 \mathrm{veh} / \mathrm{h}, 1500 \mathrm{veh} / \mathrm{h}, 2000 \mathrm{veh} / \mathrm{h}, 2500 \mathrm{veh} / \mathrm{h}$ respectively.

According to the possible value of above parameters, there are 600 kinds of simulation combination schemes in theory. By consulting the design engineers, and according to the principle of the priority of traffic capacity, 20 groups are selected as the combination of the simulation experiments, as shown in Table 2. The 20 combinations are simulated in the condition of a climbing lane or no climbing lane. The test of effectiveness of setting up the climbing lane is conducted through the comparative analysis.
Table 1. Design parameters combination of simulation

\begin{tabular}{|c|c|c|c|c|c|}
\hline $\begin{array}{c}\text { Group } \\
\text { number }\end{array}$ & $\begin{array}{c}\text { Longitudi } \\
\text { nal slope } \\
(\%)\end{array}$ & $\begin{array}{c}\text { Slope length } \\
\text { (m) }\end{array}$ & $\begin{array}{l}\text { Length of } \\
\text { climbing } \\
\text { lane (m) }\end{array}$ & $\begin{array}{l}\text { Proportion } \\
\text { of trucks } \\
(\%)\end{array}$ & $\begin{array}{l}\text { Traffic } \\
\text { (veh/h) }\end{array}$ \\
\hline 1 & 3 & 900 & 300 & 10 & 1000 \\
\hline 2 & 4 & 600 & 300 & 10 & 1000 \\
\hline 3 & 5 & 300 & 200 & 10 & 1000 \\
\hline 4 & 6 & 600 & 300 & 10 & 1000 \\
\hline 5 & 7 & 300 & 200 & 10 & 1000 \\
\hline 6 & 3 & 1200 & 300 & 10 & 1500 \\
\hline 7 & 4 & 600 & 300 & 10 & 1500 \\
\hline 8 & 5 & 600 & 300 & 10 & 1500 \\
\hline 9 & 6 & 300 & 200 & 10 & 1500 \\
\hline 10 & 7 & 300 & 200 & 10 & 1500 \\
\hline 11 & 3 & 1200 & 300 & 10 & 2000 \\
\hline 12 & 4 & 600 & 300 & 10 & 2000 \\
\hline 13 & 5 & 600 & 300 & 10 & 2000 \\
\hline 14 & 6 & 600 & 300 & 10 & 2000 \\
\hline 15 & 7 & 300 & 200 & 10 & 2000 \\
\hline 16 & 3 & 300 & 200 & 10 & 2500 \\
\hline 17 & 4 & 600 & 300 & 10 & 2500 \\
\hline 18 & 5 & 300 & 200 & 10 & 2500 \\
\hline 19 & 6 & 300 & 200 & 10 & 2500 \\
\hline 20 & 7 & 300 & 200 & 10 & 2500 \\
\hline
\end{tabular}

Adding a lane in the climbing section of the secondary two-lane highway, it is used for large vehicles climbing, that is the climbing lane. According to the speed prediction model of truck in steep slope, the change of the running speed of the truck is determined. VISSIM traffic simulation software is used to simulate and analyze the traffic state. The changes of traffic capacity, average speed, and travel delay and service level are studied, which provide the basis for the optimization of the length, 
slope and other parameters of the climbing lane. Among them, the traffic capacity is classified implementation according to the "Technical Standard of Highway Engineering" (JTG B01-2014).

VISSIM software is applied to simulate the micro simulation of the uphill road section of two lane highway. The specific steps are as follows: (1) Building the simulation road network of the uphill section. The simulation model of road network is established in VISSIM, and the numbers of road lanes, lane width, slope, length and so on are set up. (2) Setting traffic flow parameters. According to the experimental scheme, the road traffic volume, the proportion of vehicles, the expected vehicle speed are input to the road network model. (3) Setting traffic control parameters. Priority of traffic conflict point, give way rules, the deceleration area and speed decision-making point are carried out. Setting the climbing lane is to make fast vehicles and slow vehicles moving apart. Therefore, the traffic management and control module of the separated and convergence from main road are needed. (4) Setting evaluation module, and simulation runs and output evaluation index. (5) Analyzing the output of the evaluation parameters.

\section{Result analysis}

According to the 20 groups of combination design in Table 1, simulation analysis is carried out. The traffic capacity, driving speed, delay, saturation values of uphill section are obtained before and after the setting climbing lane. Only figures of group 1-5 are shown, while figures of other groups are similar.

\subsection{Traffic volume=1000veh $/ \mathrm{h}$, group $1-5$}

In the condition of road traffic volume $1000 \mathrm{veh} / \mathrm{h}$, the truck proportion $10 \%$ and the slope gradient $3 \%, 4 \%, 5 \%$, $6 \%, 7 \%$, the parameters of the slope length and the length of climbing lane are obtained by the five groups, namely group 1-5. The traffic capacity of section, the average speed and the delay of the car and the saturation are obtained through the numerical simulation, as shown in Fig. 1.

The simulation result analysis shows that, after setting the climbing lane, traffic capacity has increased significantly. Climbing lane enable truck and car lane driving respectively, improving the degree of freedom of the car, so the vehicle's average speed increases and the vehicle delay is low. Moreover, after setting climbing lane in the given traffic flow conditions, the degree of dispersion has a larger decline. It shows that the setting the climbing lane can increase the speed of the car, and the speed is more stable, which can effectively improve the level of climbing. After addition a climbing lane, the saturation of the main road sections are reduced to some extent, enhancing the road service level, improving the service quality of the road. It is improved from the original fourth service levels to three levels of service.

\subsection{Traffic volume=1500veh $/ \mathrm{h}$, group 6-10}

In the condition of road traffic volume $1500 \mathrm{veh} / \mathrm{h}$, the truck proportion $10 \%$ and the slope gradient $3 \%, 4 \%, 5 \%$, $6 \%, 7 \%$, the parameters of the slope length and the length of the climbing lane are obtained by the five groups, namely group 6-10.

The simulation result analysis shows that, after setting the climbing lane, traffic capacity has increased significantly. It is improved from the original fourth, fifth service level to fourth service level.

\subsection{Traffic volume=2000veh $/ \mathrm{h}$, group11-15}

In the condition of road traffic volume $2000 \mathrm{veh} / \mathrm{h}$, the truck proportion $10 \%$ and the slope gradient $3 \%, 4 \%, 5 \%$, $6 \%, 7 \%$, the parameters of the slope length and the length of the climbing lane are obtained by the five groups, namely group 11-15.

The simulation result analysis shows that, after setting the climbing lane, traffic capacity has increased significantly. It is improved from the original fifth service level upgrade for the fourth service level.

\subsection{Traffic volume=2500veh/h, group $16-20$}

In the condition of road traffic volume $2500 \mathrm{veh} / \mathrm{h}$, the truck proportion $10 \%$ and the slope gradient $3 \%, 4 \%, 5 \%$, $6 \%, 7 \%$, the parameters of the slope length and the length of the climbing lane are obtained by the five groups, namely group 16-20.

The simulation result analysis shows that, after setting the climbing lane, traffic capacity has increased significantly. It is improved from the original fourth, fifth service level upgrade to fourth service level.
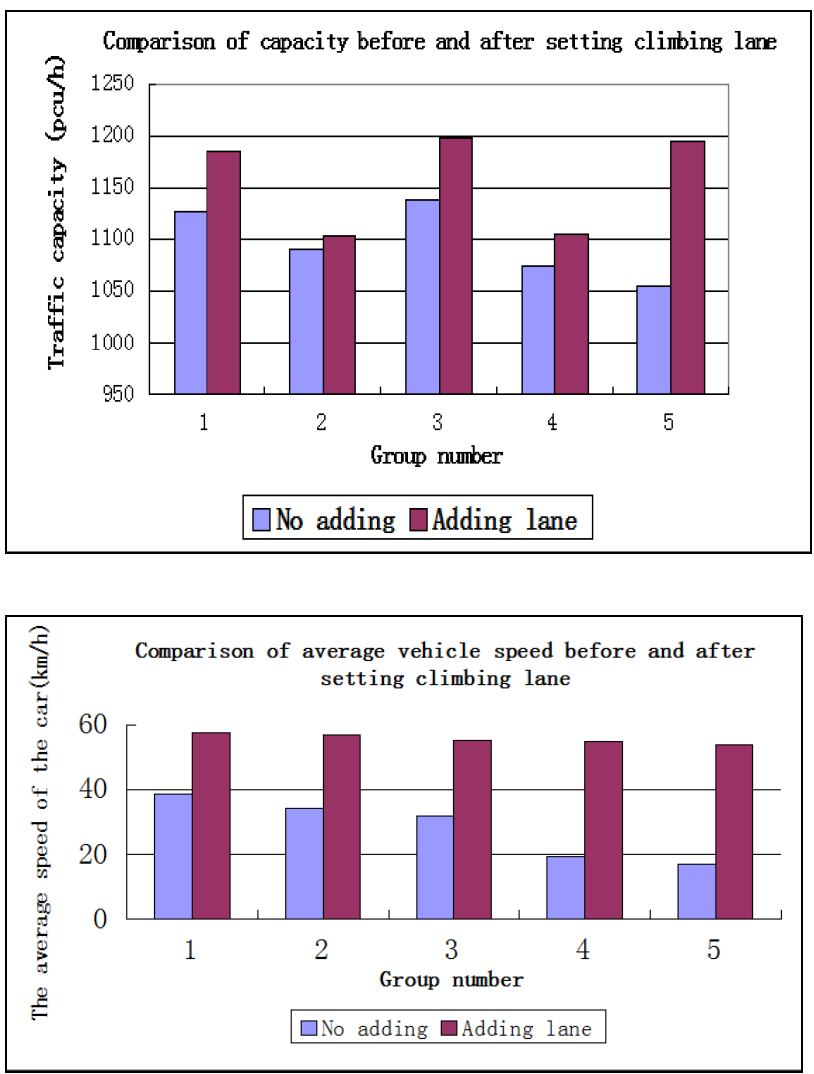

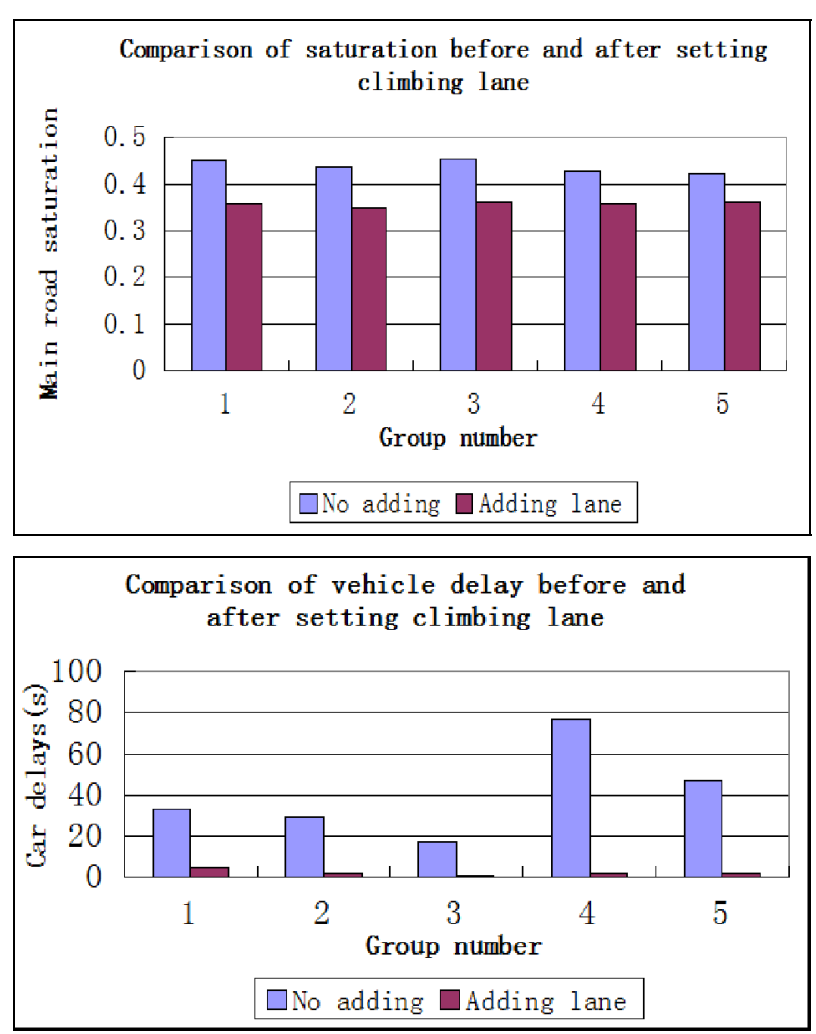

Figure 1. The comparison parameters between before and after setting climbing lane (group 1-5)

\section{Conclusion}

From numerical simulation, after setting climbing lane to mountainous double lane highway, the traffic capacity of the section, average speed increase while delays and saturation are decreased, especially in the car delays, and the level of service has increased. The results show that adding climbing lane could improve the traffic capacity, while it is conducive to road safety. It should also be noted that the effect of adding a climbing lane is not the same for different alignment and traffic combinations. As a combination of $1-5$, the traffic capacity increases by $1 \%$ $-12 \%$ while it reaches maximum when longitudinal slope is $7 \%$, average speed increases by $49 \%-218 \%$ while it reaches maximum when longitudinal slope is $7 \%$, delays decreases by $85 \%-97 \%$ while it reaches maximum when longitudinal slope is $6 \%$, saturation decreases by $14 \%$ $21 \%$ while it reaches maximum when longitudinal slope is $7 \%$.

\section{Discussion}

Factors that affect the traffic capacity on climbing section can be considered from two aspects of road and traffic. Road factors include lane number, slope gradient and slope length, while traffic factors include traffic volume, vehicle speed and proportion of trucks in whole traffic volume. Number of lanes is two in this study.

Slope gradient: The slope gradient of the road has a great influence on the traffic capacity of climbing sections. In the fixed slope length, the larger climbing gradient, the lower speed of the vehicle and traffic capacity is.

Slope length: The slope length has less influence on traffic capacity of the climbing section relative to the slope gradient. Under fixed slope gradient, the longer climbing length, the lower speed of the vehicle and traffic capacity is.

Traffic volume: In the climbing section, whole traffic volume has a certain impact on its capacity. When traffic volume is small, traffic density is low as a result of fewer vehicles in the driveway, the number of vehicles through the climbing section is less; if traffic volume is larger, there are more vehicles in the driveway in the certain lane numbers, which result in high traffic density, even reaching the saturation flow, while it could induce traffic jams seriously.

Speed: The influence of vehicle speed on traffic capacity of climbing section is mainly expressed in the dispersion of speed. The greater the dispersion of the speed, the more unstable the traffic flow is, which could result in disorder of vehicles and less traffic capacity.

Proportion of trucks: The influence of the proportion of trucks on the traffic capacity of climbing section is great. When there are more cars and fewer trucks, it will result in less lane changing behavior and stable vehicle speed, so traffic capacity of climbing road will not reduce obviously. If proportion of trucks is bigger, it will result in lower speed of climbing section and less traffic capacity. When proportion of trucks lying between of the above two cases, on the one hand, because of truck speed is low in the climbing section, it will reduce the traffic capacity, on the other hand, speed dispersion will increase due to the lane changing behavior occurs frequently, which will also cause reduced traffic capacity.

20 simulated combination models containing alignment and traffic parameters are chosen to explore the effect of climbing lane. Adding climbing lane could effectively increase traffic capacity and average speed while decrease delays and saturation. Different combination has different effect. The length of climbing lane is contained in the slope length, so various proportions of climbing lane result in much simulated results. While the length of the climbing lane is related to that how much trucks could travel on the climbing lane at the same time. The position of climbing lane in the uphill highway, separated and convergence from main road, which are also factors influencing traffic capacity, requires further study.

\section{Acknowledgment}

This work was funded by the National Science and Technology Support Program of China (No. 2015BAK09B00, 2015BAK09B01，2015BAK09B02), Chongqing Science \& Technology Commission (No. cstc2014yykfb30001, cstc2014jesf30001, cstc2015shmszx30007). It was also funded by Guizhou Transportation Science and Technology Project of Guizhou Provincial Transportation Department (No. 2015-121-035). 


\section{References}

1. R.R. Tian, Q.J. Xiang, S.T. Hu. Research on Traffic Safety of Freeway Upgrade Section. Procedia Social and Behavioral Sciences, 96, 548-556, 2013.

2. M.J. Cassidy, K.Kim, W.Ni, W.H. Gu. A problem of limited-access special lanes. Part I: Spatiotemporal studies of real freeway traffic. Transportation Research Part A, 80, 307-319, 2015.

3. S. Labi. Efficacies of roadway safety improvements across functional subclasses of rural two-lane highways. Journal of Safety Research, 42, 231-239, 2011.
4. M.J. Cassidy, K.Kim, W. Ni, W.H Gu. A problem of limited-access special lanes. Part I: Spatiotemporal studies of real freeway traffic. Transportation Research Part A, 80, 320-329, 2015.

5. Y.R. Kim, S.K. Lee, J.P. Moon, J.H. Jeong, J.S. Choi. A Study on Appropriate length of Passing Lane in Consideration of Traffic Characteristics of Two-Lane Roads in South Korea. Procedia - Social and Behavioral Sciences, 43, 671-680, 2012.

6. C.Y. Zhuang. Design of climbing lane in mountainous freeway based on vehicl dynamic performance. Xi'an, Chang'an University, 2006. 